\title{
ERROS COMUNS DE INTERPRETAÇÃO DE RESSONÂNCIA MAGNÉTICA DE JOELHO: COMO RECONHECÊ-LOS E EVITÁ-LOS*
}

\author{
Valdair Francisco Muglia1, Marcelo Novelino Simão1, Jorge Elias Júnior², Clóvis Simão Trad²
}

Resumo A ressonância magnética tornou-se o método de imagem de escolha para o estudo das articulações, devido a sua grande diferenciação tecidual, resolução de estruturas, imagens em múltiplos planos e estudos dinâmicos (cinemáticos). Talvez a articulação do joelho seja o exame de ressonância magnética mais solicitado na área osteoarticular. $O$ conhecimento detalhado da anatomia, fisiologia e aspecto de imagenologia da região permite uma interpretação adequada dos exames. No entanto, por vezes, estruturas anatômicas que só aparecem esporadicamente, variantes anatômicas e artefatos podem causar erros de interpretação desses exames. $O$ presente artigo tem por finalidade discutir as causas mais freqüentes de erros de interpretação, suas causas e como evitá-los.

Unitermos: Ressonância magnética. Joelho. Artefatos. Erros. Pseudolesões.

Abstract Pitfalls of magnetic resonance imaging of the knee: how to recognize and avoid them.

Magnetic resonance imaging has become the first choice imaging method for the evaluation of the joints due to its exceptional tissue differentiation, high resolution, multiplanar images and kinematics studies. The knee is probably the most common joint evaluated by magnetic resonance imaging and the knowledge of anatomy, physiology and imaging features is essential for an accurate interpretation of these studies. However, anatomical structures that are only observed sporadically, normal variants and artifacts may sometimes make it difficult to interpret these examinations. The purpose of this article is to review the most frequent pitfalls of magnetic resonance imaging of the knee, discuss their causes and how to avoid them.

Key words: Magnetic resonance imaging. Knee. Pitfalls. Errors. Pseudolesions.

\section{INTRODUÇÃO}

Nos últimos anos, a ressonância magnética (RM) tem-se fixado como o meio de diagnóstico por imagem mais importante na investigação das doenças osteoarticulares. A alta especificidade e sensibilidade do método é fruto da obtenção de imagens de alta definição, em múltiplos planos de estudo, associada a uma grande capacidade de caracterização tecidual. Ademais, o método fornece informações variadas, contando com a vantagem de não ser invasivo.

O estudo das articulações, em particular, tem sido uma das principais aplicações da RM. Nesta área, o estudo das patologias do joelho tem ganho enfoque especial, devido à sua aplicação na me-

* Trabalho realizado no Hospital das Clínicas da Faculdade de Medicina de Ribeirão Preto da Universidade de São Paulo (FMRP-USP), Ribeirão Preto, SP.

1. Médicos Assistentes do Centro de Ciências das Imagens e Física Médica do Hospital das Clínicas da FMRPUSP.

2. Docentes de Radiologia do Centro de Ciências das Imagens e Física Médica da FMRP-USP.

Endereço para correspondência: Dr. Valdair Francisco Muglia. Centro de Ciências das Imagens e Física Médica, FMRP-USP. Avenida Bandeirantes, 3900. Ribeirão Preto, SP 14040-030

Aceito para publicação em 14/12/2000. dicina esportiva e lesões traumáticas. No Hospital das Clínicas da Faculdade de Medicina de Ribeirão Preto da Universidade de São Paulo (HCFMRP-USP), de 1997 a 1999 foram realizados 526 exames de RM da articulação do joelho.

Métodos tradicionais, como a pneumoartrografia, apesar de apresentarem boa sensibilidade, especialmente nas lesões meniscais, nas mãos de profissionais experientes, não permitem avaliação adequada de várias estruturas desta articulação, como os ligamentos cruzados, colaterais e os componentes do aparelho extensor do joelho.

$\mathrm{Na}$ busca de maiores informações, a ultra-sonografia e a pneumoartrotomografia (pneumoartro-TC) também foram utilizadas, porém sem resultados brilhantes. Todos esses métodos, excetuando-se a ultra-sonografia, ainda possuem o inconveniente de serem invasivos.

$\mathrm{O}$ estudo das patologias do joelho pela RM está bem estabelecido, com vários excelentes textos documentando extensivamente o assunto.

$\mathrm{O}$ presente artigo tem por finalidade apontar e discutir situações em que, freqüentemente, são observados erros de interpretação. As causas mais comuns para estes erros são:

a) presença de estruturas que não são vistas em todos os exames, e quando aparecem podem ser tomadas por sinais patológicos;

b) variações anatômicas de ocorrência esporádica;

c) artefatos inerentes ao método, que podem aparecer em determinadas sequiências e com certos parâmetros.

Este estudo é especialmente dirigido para os que, iniciando no método, necessitam se familiarizar com tais armadilhas ("pitfalls").

\section{LESÕES GRAU II vs GRAU III}

As lesões meniscais são classificadas, à RM, em graus I, II e III, segundo critérios morfológicos. Tal classificação apresenta boa correlação com achados cirúrgicos e histológicos ${ }^{(1,2)}$.

Recentemente, uma nova classificação foi sugerida, e apesar de bem difundida, a sistematização descrita acima permanece como a mais utilizada ${ }^{(3)}$.

As lesões grau I são definidas como áreas de hiperintensidade intrameniscais 
que não se estendem à superfície articular. Representam alterações degenerativas iniciais, com depleção celular e degeneração mucinosa, não sendo, habitualmente, detectadas à cirurgia ${ }^{(4)}$.

As lesões grau II correspondem a extensas áreas de degeneração mucinosa ou hialóide, sem plano de clivagem definido. Aparecem como lesões de sinal hiperintenso, lineares, podendo ou não se estender até a margem do menisco, porém sem apresentar nítida comunicação com a cavidade articular ${ }^{(\mathbf{5 , 6})}$.

As lesões grau III apresentam comunicação bem estabelecida com a cavidade articular, representando o sinal mais específico, porém não-patognomônico, da fratura de menisco.

As lesões grau II representam alterações degenerativas mais acentuadas, denotando um menisco mais propenso a apresentar fratura $^{(7)}$. No entanto, esporadicamente, são encontrados casos nos quais a distinção entre graus II e III não é tão fácil ${ }^{(\mathbf{8})}$. Nestes casos, deve-se analisar, detalhadamente, a área de sinal hiperintenso, à procura de comunicações sutis com a cavidade sinovial (Figura 1).

Além disso, deve-se observar as margens deste sinal hiperintenso. As lesões cuja borda voltada para a superfície meniscal é mais larga (vai-se "abrindo" nesta direção) habitualmente correspondem a grau III (fraturas). Lesões cuja extremidade voltada para a superfície meniscal é fina e pouco nítida geralmente são de grau II. No entanto, um pequeno número de lesões do tipo III não corresponde a fratura quando vistas à artroscopia ou pode corresponder a lesões crônicas cicatrizadas. Geralmente, nestes casos, a lesão é vista apenas em uma só imagem e em um só plano ${ }^{(8)}$.

\section{LIGAMENTOS MENISCO- MENISCAIS}

São ligamentos que ligam os dois meniscos. O ligamento que mais comumente causa problemas na interpretação diagnóstica é o transverso anterior, que une os cornos anteriores de ambos os meniscos. Localiza-se entre a inserção tibial do ligamento cruzado anterior e a gordura anterior de Hoffa. Quando o tecido adiposo do coxim gorduroso de Hoffa se interpõe entre o menisco e o ligamento transverso, a hiperintensidade da gordura pode ser confundida com lesão do corno anterior do menisco. Isto ocorre com mais freqüência no lateral, mas também pode ser visto no medial ${ }^{(9)}$.
O acompanhamento de cortes contíguos pode, facilmente, revelar o ligamento e a verdadeira natureza da hiperintensidade $^{(10)}$ (Figura 2). Também a avaliação do restante do menisco é elucidativa, uma vez que lesões isoladas do corno anterior são relativamente raras, principalmente no menisco lateral.

Outros ligamentos que podem causar dificuldades diagnósticas são o transverso posterior, observado em $1 \%$ a $4 \%$ dos casos, e os menisco-meniscais oblíquos, que se estendem do corno anterior de um menisco para o posterior do outro, sendo identificados como ligamentos medial ou lateral, conforme sua origem anterior ${ }^{(11)}$. Embora infreqüentes, em seus trajetos, por entre os ligamentos cruzados, anterior e posterior, podem ser confundidos com fragmento meniscal.

\section{TENDÃO POPLÍTEO}

O músculo poplíteo situa-se na face posterior do terço proximal da coxa. Está inserido na face posterior da tíbia, acima da linha soleal. A sua aponeurose se adere ao arco posterior do menisco lateral. A contração deste músculo traciona o menisco posteriormente, durante a flexão e rotação do joelho ${ }^{(12)}$.

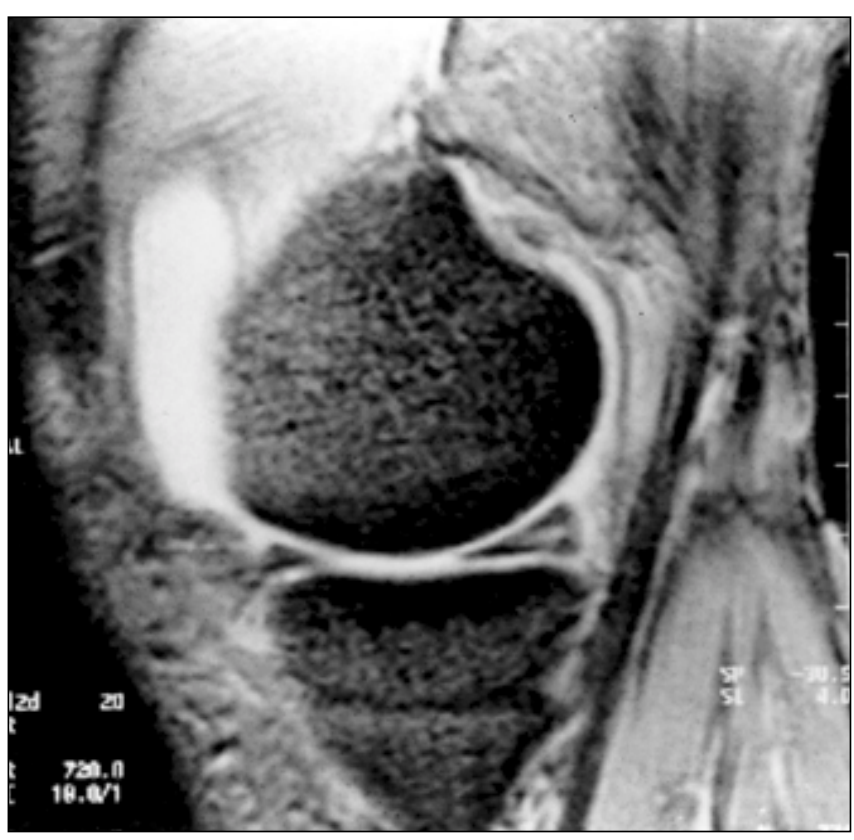

A

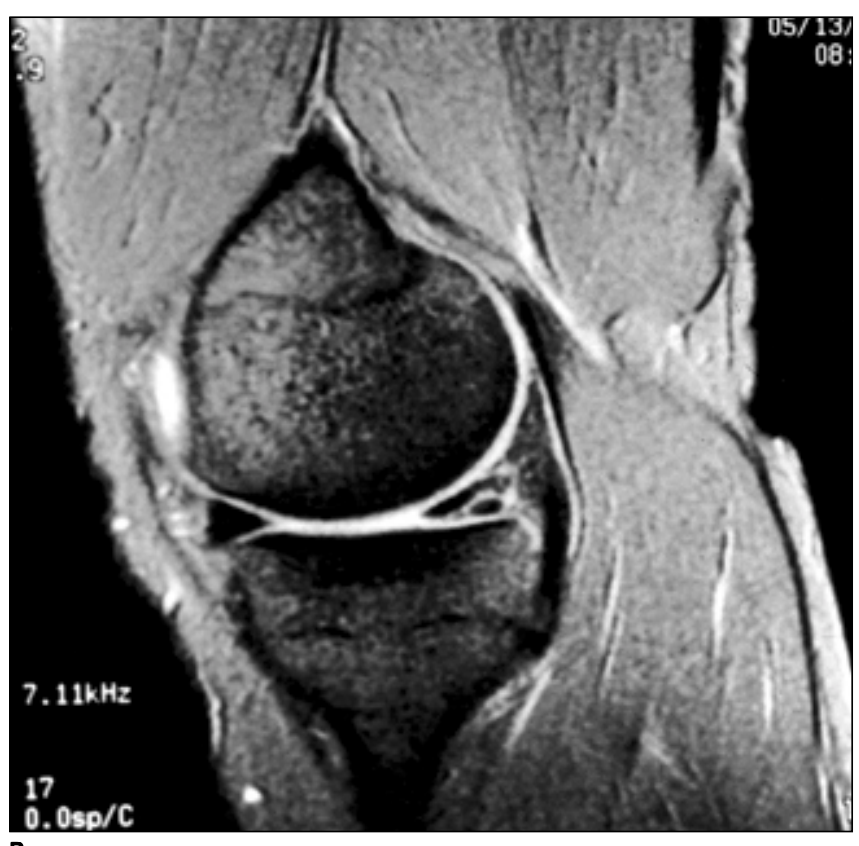

B

Figura 1. A: Seqüência sagital GE-T2 demonstra imagem linear de hipersinal no corno posterior do menisco medial, que não atinge a superfície articular. B: Seqüência sagital GE-T2 mostra imagem linear, oblíqua, estendendo-se à superfície articular inferior. 


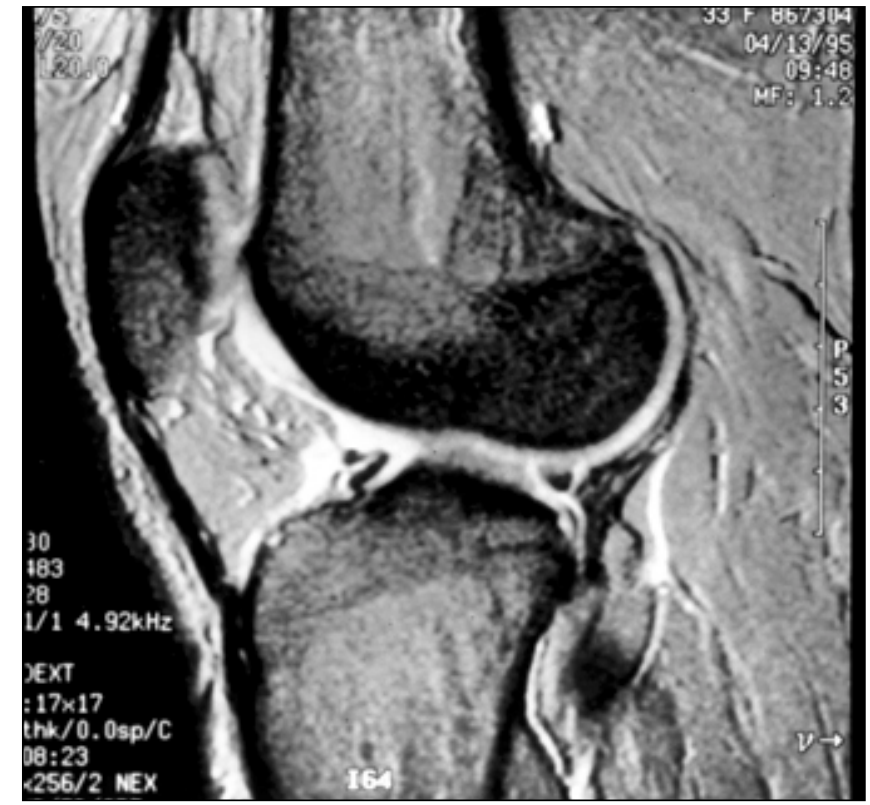

A

Figura 2. A: Seqüência sagital GE-T2 mostra ligamento transverso junto ao corno anterior do menisco lateral, separados por imagem de alto sinal, que simula fratura meniscal. B: Seqüência sagital GE-T2. Corte adjacente, em que se observa a inserção do ligamento junto ao menisco. Incidentalmente, observa-se fratura vertical do corno posterior. C: Seqüência axial TSE-DP com FATSAT evidencia o ligamento transverso em toda a sua extensão, incluindo-se as terminações meniscais.

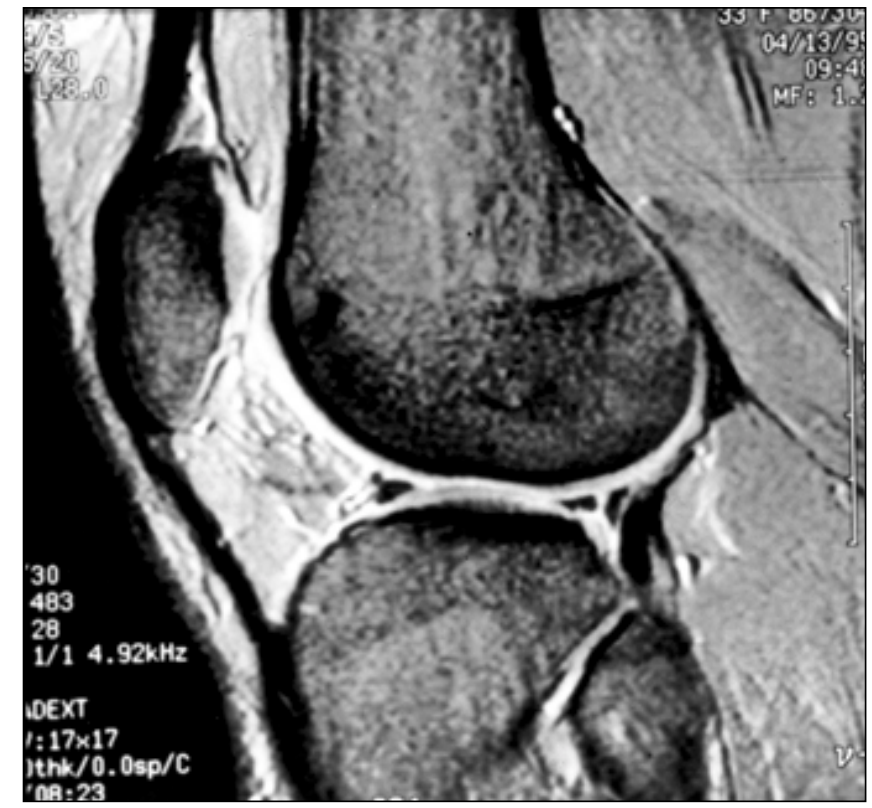

B

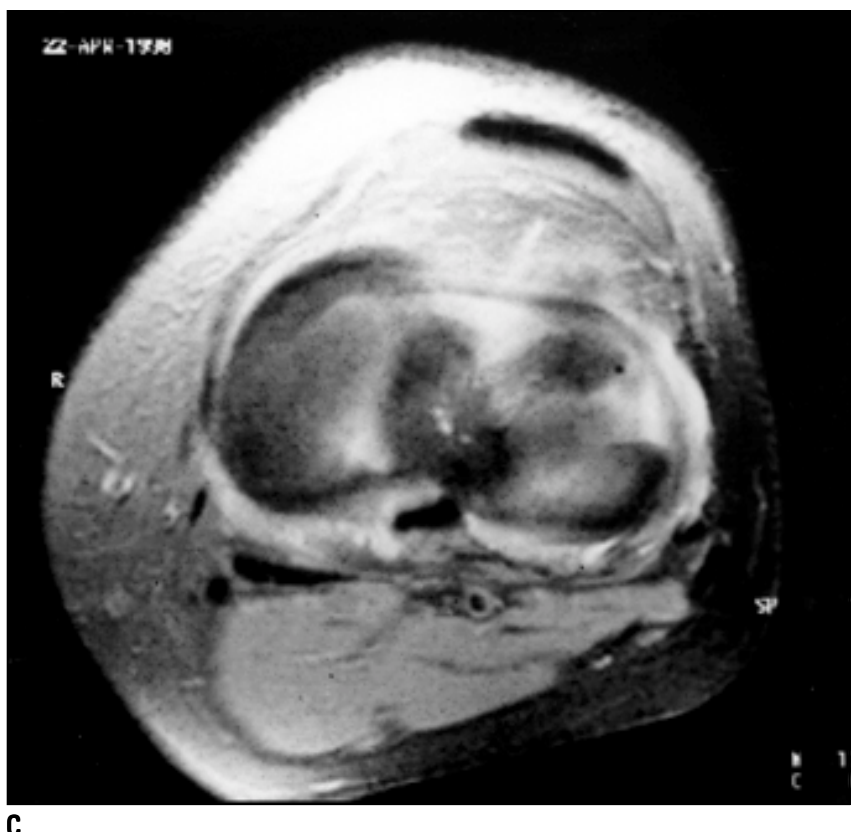

O seu tendão tem curso oblíquo, no sentido médio-lateral e póstero-anterior, indo se inserir no côndilo femoral lateral. O tendão e a sua bainha são estruturas intra-articulares que se interpõem entre o menisco, a cápsula articular e o ligamento colateral lateral ${ }^{(13)}$.

A bainha do tendão poplíteo aparece como uma hiperintensidade linear, que pode ser confundida com lesão do corno posterior do menisco lateral. A orientação desta imagem de sinal hiperintenso, como descrita acima, e o acompanhamen- to do tendão/músculo nos cortes adjacentes garantirão a correta identificação desta estrutura (Figura 3).

\section{FIBRILAÇÃ O}

A presença de fibrilas na face livre e côncava dos meniscos, que está voltada internamente, é vista como área de hipersinal nos cortes sagitais e coronais. Este aumento de sinal não corresponde a lesão meniscal, exceto quando uma aparência anormal do menisco, ou outro achado associado, corrobore a hipótese de uma possível lesão ${ }^{(13)}$.

\section{LIGAMENTO MENISCO. FEMORAL}

O ligamento menisco-femoral une a face medial do corno posterior do menisco lateral à face externa do côndilo femoral lateral, e apresenta dois componentes. Um componente anterior ao ligamento cruzado posterior (LCP), que recebe o nome de ligamento de Humphrey, é mais 

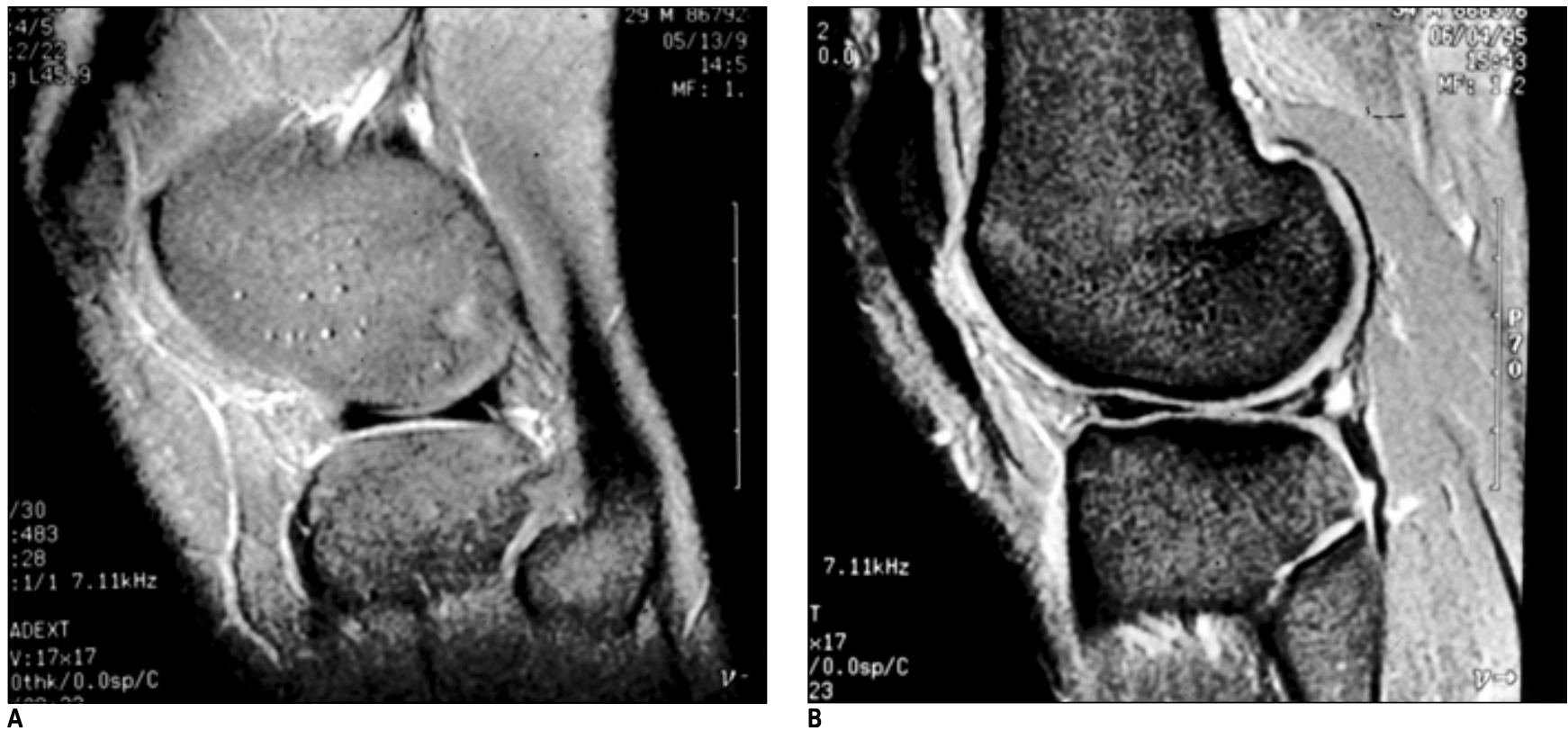

A

B

Figura 3. A: Seqüência sagital GE-T2 mostra imagem linear de alto sinal entre o corno posterior do menisco lateral e o tendão poplíteo, simulando fratura. Observar que o sentido da pseudolesão (de posterior para anterior e inferior para superior) é o mesmo do trajeto do tendão. B: Seqüência sagital GE-T2 evidencia, inferiormente, o tendão poplíteo e fratura do corno posterior, com sentido diferente do trajeto do tendão.

bem observado nos cortes sagitais, como uma pequena estrutura de sinal hipointenso, abaixo da face côncava do LCP. O segundo componente localiza-se posteriormente ao LCP, podendo ser visto nos cortes sagitais, acima da face convexa do LCP, ou nos cortes coronais posteriores. Esta segunda porção recebe o nome de ligamento de Wrisberg. Estas estruturas são visibilizadas em apenas $50 \%$ dos exames realizados ${ }^{(14)}$.

Próximo à sua inserção meniscal, este ligamento pode simular uma lesão meniscal, na porção mais interna do corno posterior do menisco lateral (Figura 4).

\section{EFEITO DE VOLUME PARCIAL}

Este artefato é muito comum nos cortes periféricos, tanto laterais como mediais, aparecendo como imagem linear hiperintensa, intrameniscal, geralmente na porção média. Este efeito também é o responsável pelo aparecimento de uma hiperintensidade, na face côncava dos cornos posteriores dos meniscos, nos cortes sagitais. Em ambas as situações o hipersinal é devido ao efeito de volume parcial da gordura e elementos vásculonervosos $^{(\mathbf{1 5})}$. Os cortes coronais confirmam a integridade dos meniscos.

\section{ARTÉRIA GENICULADA LATERAL INFERIOR}

Este vaso é um ramo da artéria poplítea, que se origina na região da articulação tibiofemoral e segue em direção lateral na face anterior do joelho. Pode ocasionar erro de interpretação quando se encontra junto ao corno anterior do menisco lateral.

$\mathrm{O}$ espaço entre o menisco e a artéria, geralmente com hipersinal, pode simular lesão do tipo III ${ }^{(\mathbf{1 5})}$, de modo semelhante ao ligamento transverso.

\section{MENISCO PSEUDODISCÓIDE}

O diagnóstico de menisco discóide deve ser definido nos cortes sagitais, nos casos em que, em três cortes consecutivos de no mínimo $3 \mathrm{~mm}$, o menisco é visibilizado com o aspecto de "gravata borboleta". Nos cortes coronais, uma vez que os cornos posteriores podem apresentarse como uma faixa horizontal contínua, deve-se ter a certeza de que a porção avaliada corresponde ao corpo do menisco, o que normalmente coincide com a primeira ou segunda imagem coronal, na qual se observa a eminência intercondilar $^{(\mathbf{1 6})}$.

\section{ARTEFATOS ORIGINÁRIOS DA PULSAÇÃO DA ARTÉRIA POPLÍTEA}

Alguns desses artefatos podem ser reconhecidos nos cortes sagitais e, principalmente, nos coronais. No entanto, na maioria das vezes esses artefatos são grosseiros e de fácil reconhecimento. Nas situações em que inversão da direção de codificação de fase é utilizada, para evitar os artefatos de pulsação da artéria poplítea, um artefato do tipo truncamento ("truncation") pode aparecer nos cornos posteriores dos meniscos, principalmente se uma matriz $128 \times 128$ for utilizada $^{(17)}$ (Figura 5).

\section{MEDULA VERMELHA RESIDUAL}

Este achado não é raro no fêmur distal, ou tíbia proximal, em adultos sadios. Pode envolver uma área extensa e simular doença infiltrativa medular. Deve ser lembrado sempre que a alteração de sinal poupe a epífise e a patela e, principalmente, quando não houver elevação significativa do sinal em T2. A história clínica e os dados laboratoriais podem esclarecer eventuais dúvidas ${ }^{(18)}$. 


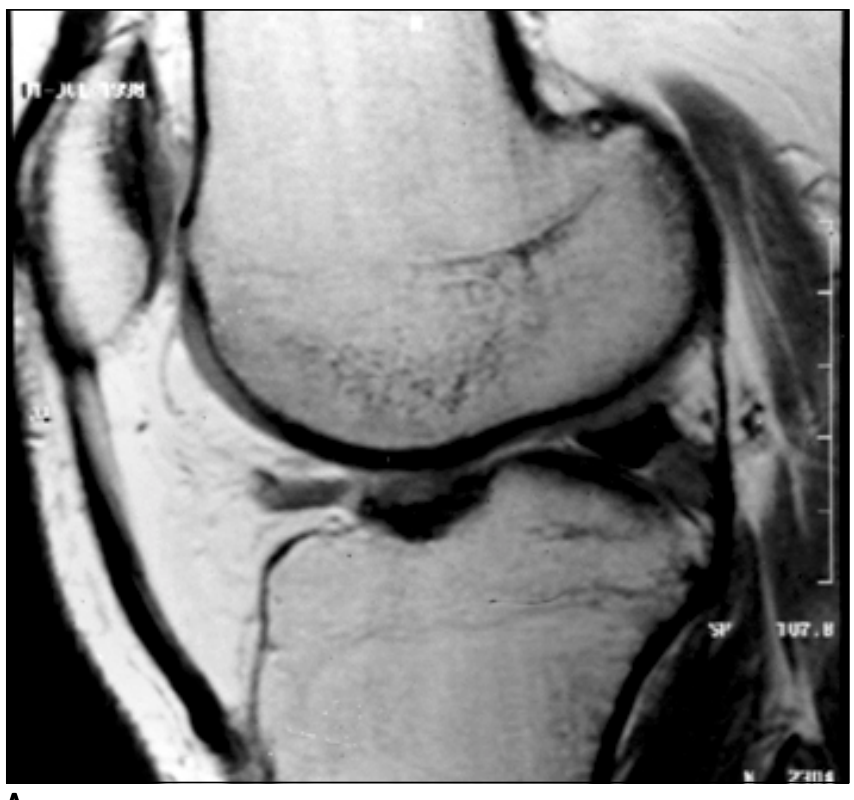

A

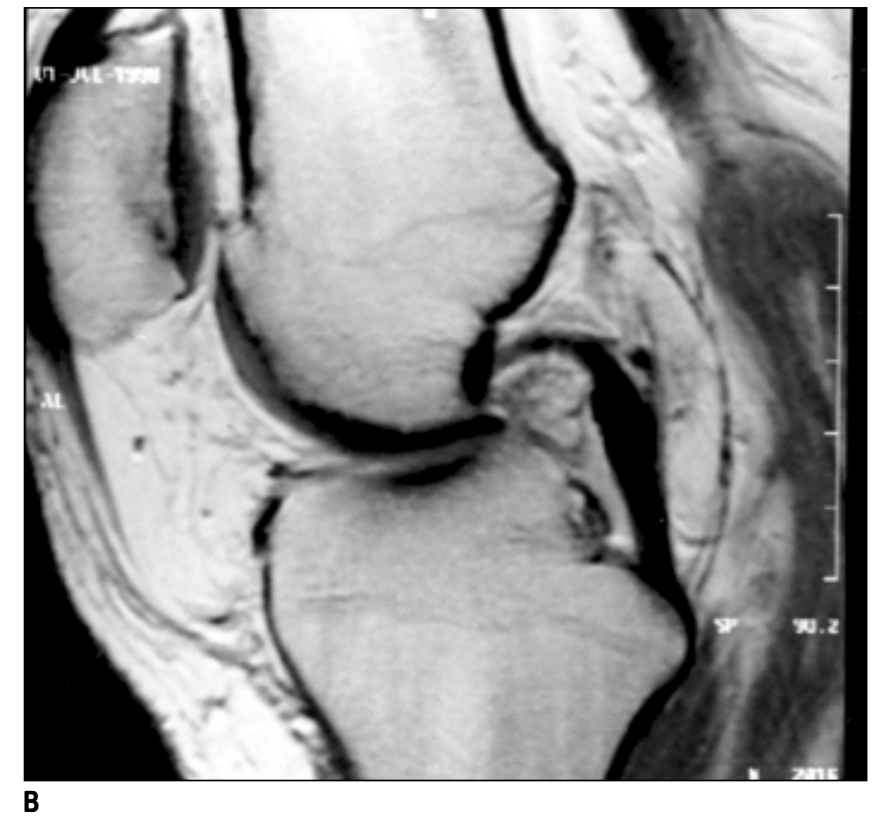

B

Figura 4. A: Seqüência sagital DP mostra traço de hipersinal na região póstero-superior, entre o ligamento meniscofemoral posterior (Wrisberg) e 0 menisco, simulando lesão. B: Seqüência sagital DP, corte adjacente, mostra o ligamento de Wrisberg e sua relação com o cruzado posterior.

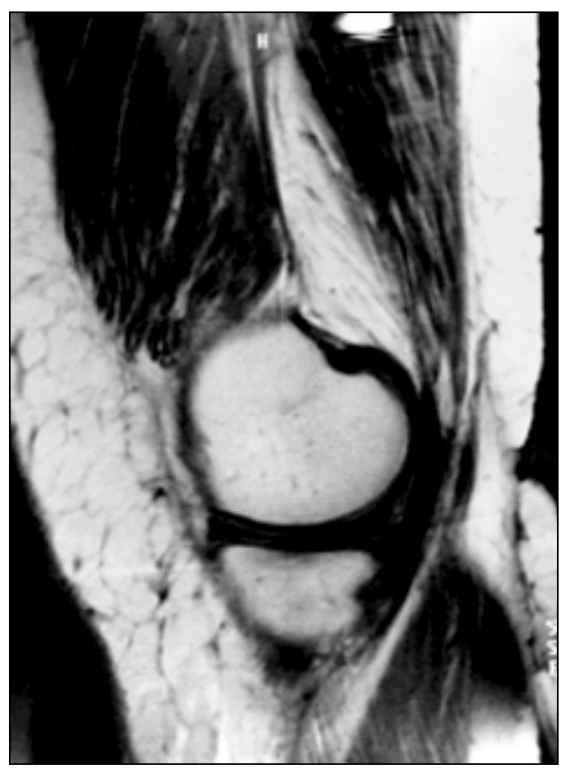

Figura 5. Seqüência sagital T1 evidencia artefato linear, por inversão da direção de codificação de fase, interferindo na avaliação do menisco medial.

\section{TENDÃo PATELAR}

O tendão patelar é visibilizado em toda sua extensão nos cortes sagitais. Os cortes axiais também podem fornecer informações adicionais no estudo desta estrutura. O sinal habitualmente visto é de baixa intensidade e homogêneo; no entanto, em alguns casos, hiperintensidade pode ser vista numa área um pouco acima da sua inserção na tuberosidade da tíbia. Esta área carece de significado patológico, representando um artefato de imagem, que não deve ser interpretado erroneamente, de modo diverso( ${ }^{(8)}$.

\section{BURSA DO LIGAMENTO COLATERAL MEDIAL}

Localizada entre o ligamento colateral tibial e a cápsula, na altura da fenda articular. Quando distendida, com líquido no seu interior, pode ser vista na RM, o que realmente traduz uma condição patológica. A bursite deve ser considerada nos casos em que existe quadro clínico de dor medial que melhora com a injeção de corticóide e a RM mostra distensão da bursa, podendo o menisco estar íntegro ou lesado.

Entre os diagnósticos diferenciais da bursite incluem-se a separação meniscocapsular e o cisto parameniscal, que é mais comumente associado a fissura horizontal do menisco ${ }^{(19)}$.

\section{EFEITO DO ÂNGULO MÁGICO}

Este artefato manifesta-se por uma pequena área de alto sinal na porção mais medial do corno posterior do menisco lateral, observada nas sequiências com TR curto (TE < $20 \mathrm{~ms}$, nas sequiências spin-eco), simulando lesão degenerativa. Esta área é o efeito do ângulo mágico, fenômeno que ocorre quando uma estrutura de arranjo fibrilar encontra-se orientada entre 55 e 60 graus em relação ao campo magnético principal ${ }^{(20)}$.

\section{ASPECTO SERRILHADO DO MENISCO ("SPECKLED")}

A porção medial do corno anterior do menisco lateral pode apresentar um alto sinal com aspecto serrilhado, sem significado patológico. Esta imagem deve aparecer apenas nos dois cortes mais mediais do menisco. Provavelmente, é decorrente da inserção de fibras do ligamento cruzado anterior e aparece em $64 \%$ dos $\operatorname{casos}^{(21)}$ (Figura 6).

\section{MENISCO FANTASMA}

Após meniscectomia, uma estrutura simulando o menisco deformado pode ser vista em sua topografia, possivelmente representando tecido fibroso no local ${ }^{(22)}$. O conhecimento da história clínica orienta facilmente para o diagnóstico correto. 


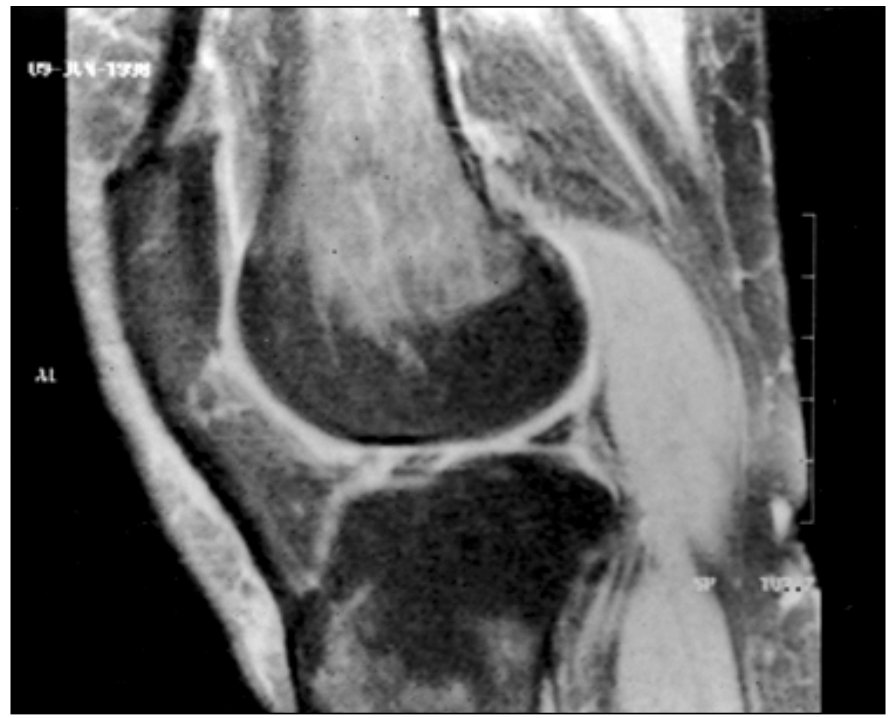

Figura 6. Seqüência sagital FSE-DP com FATSAT mostra aspecto serrilhado com alto sinal no seu interior, visto na porção mais interna do corno anterior do menisco lateral, simulando lesão. Notase substituição gordurosa nas epífises.

Tabela 1.

\begin{tabular}{|l|l|l|}
\hline 1. Menisco lateral & - Corno posterior & $\begin{array}{l}\text { - Tendão poplíteo } \\
\text { - Ligamentos meniscofemorais } \\
\end{array}$ \\
& & $\begin{array}{l}\text { - Pulsação da artéria poplítea } \\
\text { - Efeito do ângulo mágico }\end{array}$ \\
\cline { 2 - 3 } & - Corno anterior & $\begin{array}{l}\text { - Ligamento transverso } \\
\text { - Aspecto serrilhado }\end{array}$ \\
\hline 2. Menisco medial & - Bursa do ligamento colateral medial \\
& - Aspecto ondulado ("flounce") \\
\hline
\end{tabular}

\section{ASPECTO ONDULADO ("FLOUNCE")}

Representa o aspecto ondulado que pode aparecer no menisco medial. É considerado variante do normal, provavelmente devido à frouxidão ligamentar ${ }^{(23)}$.

A Tabela 1 resume os locais e os artefatos mais freqüentemente encontrados.

\section{REFERÊNCIAS}

1. Crues JV, Mink J, Levy TL, Lotysch M, Stoller
DW. Meniscal tears of the knee: accuracy of MR imaging. Radiology 1987;164:445-8.

2. Stoller DW, Martin C, Crues JV, Kaplan L, Mink JH. Meniscal tears: pathological correlation with MR imaging. Radiology 1987;163:731-5.

3. Dillon EH, Pope CF, Jokl P, Lynch K. The clinical significance of stage 2 meniscal abnormalities on magnetic resonance knee images. Magn Reson Imaging 1990;8:411-5.

4. Dillon EH, Pope CF, Jok1 P, Lynch K. Follow-up of grade 2 meniscal abnormalities in the stable knee. Radiology 1991;181:849-52.

5. Negendank WG, Fernandez-Madrid FR, Heilbrun LK, Teitze RA. Magnetic resonance imaging of meniscal degeneration in asymptomatic knees. $\mathbf{J}$
Orthop Res 1990;8:311-20.

6. De Smet AA, Norris MA, Yandow DR, Quintana FA, Graf BK, Keene JS. MR diagnosis of meniscal tears of the knee: importance of high signal in the meniscus that extends to the surface. AJR 1993 161:101-7.

7. Ferrer-Roca KA, Vilalta C. Lesions of the meniscus. Part I: macroscopic and hystologic findings. Clin Orthop 1980;(146):289-300.

8. Schweitzer ME, Mitchell DG, Ehrlich SM. The patelar tendon: thickening, internal signal buckling and other MR variants. Skeletal Radiol 1993; 22:411-6.

9. Watanabe AT, Carter BC, Teitelbaum GP, Seeger LL, Bradley WG. Normal variations MR imaging of the knee: appearance and frequency. AJR 1989; 155:341-4.

10. Vahey TN, Bennett HT, Arrington LE, Shelbourne KD, Ng J. MR imaging of the knee: pseudotear of the lateral meniscus caused by the meniscofemoral ligament. AJR 1990;154:1237-9.

11. Herman LJ, Beltran J. Pitfalls in MR imaging of the knee. Radiology 1988;167:775-81.

12. Stoller D. MRI of the knee. In: Edelman R, Hesselink JR, Zlatkin M, eds. Clinical magnetic resonance imaging. 2nd ed. Philadelphia: Saunders, 1997:1917-72.

13. Turner DA, Rapoport MI, Erwin WD, McGould M, Silvers RI. Truncation artifact: a potential pitfall in MR imaging of the menisci of the knee. Radiology 1991;179:629-33.

14. Tria AJ Jr, Johnson CD, Zawadsky JP. The popliteus tendon. J Bone Joint Surg 1989;71:714-6.

15. Mesgarzadeh M, Moyer R, Leder DS, et al. MR imaging of the knee: expanded classification and pitfalls to the interpretation of meniscal tears. RadioGraphics 1993;13:489-500.

16. Stoller DW. Magnetic resonance imaging in orthopaedics and sports medicine. 2nd ed. New York: Lippincott-Raven, 1997:290-1.

17. Helms CA. Pitfalls of knee MRI. In: Munk PL, Helms CA, eds. MRI of the knee. 2nd ed. New York: Lippincott-Raven, 1996:137-8.

18. Chan WP, Lang P, Genant HK. MRI of the musculoskeletal system. 1st ed. Philadelphia: Saunders, 1996:344.

19. Lee JK, Yao L. Tibial collateral ligament bursa: MR imaging. Radiology 1991;178:855-7.

20. Peterfy CG, Janzen DL, Tirman PF, van Dijke CF, Pollack M, Genant HK. "Magic angle" phenomenon: a cause of increased signal in the normal lateral meniscus on short-TE MR images of the knee. AJR 1994;163:149-54.

21. Shankman S, Beltran J, Melamed E, Rosenberg ZS. Anterior horn of the lateral meniscus: another potential pitfall in MR imaging of the knee. Radiology 1997;204:181-4.

22. Higgins CB, Hricak H, Helms CA. Magnetic resonance imaging of the body. 3rd ed. New York: Lippincott-Raven, 1996:1141-3.

23. Chew FS. Medial meniscal flounce: demonstration on MR imaging of the knee. AJR 1990;155:199. 